\title{
Um Sobrevoo Panorâmico sobre as Estratégias de Curricularização da Extensão adotadas atualmente em Cursos de Sistemas de Informação no Brasil
}

\author{
Marcílio Ferreira de Souza Júnior ${ }^{1}$, Mônica Ximenes Carneiro da Cunha ${ }^{2}$ \\ ${ }^{1}$ CODAI - Universidade Federal Rural de Pernambuco (UFRPE) \\ São Lourenço da Mata - PE - Brasil \\ ${ }^{2} \mathrm{CINFO}$ - Campus Maceió - Instituto Federal de Alagoas (IFAL) \\ Maceió - AL - Brasil \\ marcilio.souzajr@ufrpe.br, monica@ifal.edu.br
}

\begin{abstract}
The extension practice regulation as a mandatory curricular component in the undergraduate courses pedagogical projects has presented itself as a challenge. This article aims to present an overview of the extension curricularization strategies adopted in the Bachelor of Information Systems courses to date. Methodology adopted involved a documentary research on the courses' institutional websites themselves and a bibliographic research for experiences reports. The results signaled that, timidly, the educational institutions are reformulating their pedagogical projects and that the strategies commonly adopted are those that involved specific disciplines for extension or projects and programs in the service to the community.
\end{abstract}

Resumo. A regulamentação da prática extensionista como componente curricular obrigatório nos projetos pedagógicos dos cursos de graduação tem se apresentado como um desafio. Este artigo tem como objetivo apresentar um panorama sobre as estratégias de curricularização da extensão adotadas nos cursos de Bacharelado em Sistemas de Informação (BSI) até o presente momento. A metodologia adotada envolveu uma pesquisa documental nos sites institucionais dos próprios cursos e uma pesquisa bibliográfica por relatos de experiências. Os resultados sinalizaram que, timidamente, as instituições de ensino estão reformulando seus projetos pedagógicos e que as estratégias comumente adotadas são aquelas que envolveram disciplinas específicas de extensão ou de projetos e programas no atendimento à comunidade.

\section{Introdução}

A curricularização da extensão, na qual a prática extensionista deixa de ser componente complementar e opcional para se tornar obrigatório nos currículos dos cursos de graduação, foi regulamentada em 2018 através de uma resolução específica do Ministério da Educação (MEC), que instituiu as diretrizes que devem ser observadas na gestão e na avaliação das instituições de ensino superior (IES) do país [BRASIL 2018].

A inserção da extensão como componente curricular, a partir de suas novas diretrizes nacionais, visa o fortalecimento do compromisso social das IES no atendimento às demandas sociais, econômicas e culturais da sociedade por intermédio de atividades obrigatórias [Imperatore 2019], além do cumprimento de meta fixada anteriormente pelo 
Plano Nacional de Educação (PNE) 2014-2024, que define a utilização de 10\% da carga horária dos cursos superiores para esta prática [Imperatore, Pedde e Imperatore 2015].

A referida meta do PNE apresentou-se como um desafio para reformulação dos currículos dos cursos, que eram voltados para o cômputo de atividades extensionistas como extracurriculares ou complementares e deverão ser encaradas como creditação de carga horária tal como os demais componentes curriculares, proporcionando aos discentes o desenvolvimento de consciência cidadã em paralelo à formação profissional devido à ampliação e cumprimento de atividades extensionistas ao longo do curso [Serva 2020].

Assim como nas demais áreas, os Projetos Pedagógicos dos Cursos (PPCs) de Bacharelado em Sistemas de Informação (BSI) também precisaram se adequar à nova realidade regulatória. No Brasil, conforme os dados divulgados no último ciclo avaliativo do INEP ${ }^{1}$, em 2017, há 471 cursos de BSI reconhecidos pelo MEC. Passados 27 meses desde a homologação das diretrizes e restando 9 meses até o encerramento do prazo de implantação dos dispositivos da resolução (dezembro de 2021), emergiu a seguinte questão situacional: quais estratégias foram adotadas até o presente momento pelos cursos de BSI visando a curricularização da extensão? Pretendeu-se alçar um sobrevoo panorâmico sobre os currículos dos cursos de sistemas de informação frente ao desafio de readequação dos seus projetos pedagógicos.

Face ao exposto, este artigo tem como objetivo catalogar as estratégias de curricularização da extensão adotadas atualmente pelos cursos de BSI. O restante do artigo está organizado da seguinte forma: na seção 2 é apresentada a metodologia delineada; por fim, na seção 3, são descritas algumas considerações sobre a situação atual das estratégias apontadas pelos PPC's.

\section{Metodologia}

O proceder metodológico envolveu uma pesquisa documental a partir dos arquivos dos PPC's disponíveis nos sites institucionais dos próprios cursos, complementada por uma pesquisa bibliográfica que adotou como fonte o Google Scholar à procura de relatos de experiência já publicados usando a string de busca: "curricularização AND extensão AND 'bacharelado em sistemas de informação"'. A estratégia de busca foi delineada do seguinte modo: i) obtenção da listagem dos cursos de graduação melhores pontuados no Ranking Universitário da Folha ${ }^{2}$ (RUF) 2019 e daqueles com maiores notas do Conceito Preliminar do Curso (CPC) do INEP (totalizando uma amostra de 38 cursos, dentre IES públicas e privadas); ii) busca pelos PPC's dos BSI's nos sites; e, por fim, iii) pesquisa na literatura por artigos de relatos (02 artigos foram identificados). A análise qualitativa do conteúdo dos PPC's foi realizada concomitantemente por dois pesquisadores para identificar as estratégias de extensão presentes nos currículos de cada documento considerado válido para responder a questão problematizadora. Foram incluídos apenas os documentos que tratavam explicitamente da atividade de curricularização da extensão e de sua respectiva organização didática (quer como disciplina, quer como atividade).

\footnotetext{
${ }^{1}$ Instituto Nacional de Estudos e Pesquisas Educacionais - Indicadores de Qualidade Educação Superior: https://www.gov.br/inep/pt-br/acesso-a-informacao/dados-abertos/indicadores-educacionais/indicadoresde-qualidade-da-educacao-superior. Consulta realizada em março de 2021.

${ }^{2}$ Folha de São Paulo. Disponível em https://ruf.folha.uol.com.br/2019/ranking-de-cursos/computacao/
} 


\section{Panorama das estratégias de curricularização da extensão nos BSI's}

O panorama revelado no quadro 1 foi o resultado obtido a partir das evidências de curricularização identificadas nos PPC's dos cursos de BSI que compuseram a amostra da busca, resultando em 06 (seis) cursos.

Quadro 1 - Estratégias de curricularização da extensão identificadas nos BSI

\begin{tabular}{|c|c|c|c|}
\hline Instituição do BSI & $\begin{array}{l}\text { Ano do } \\
\text { PPC }\end{array}$ & Estratégias de curricularização & Fonte consultada \\
\hline Campus & 2018 & $\begin{array}{l}\text { - Disciplinas específicas: Projeto Integrador, } \\
\text { Projeto Integrador em SI, Tecnologias Sociais } \\
\text { e Assistivas } \\
\text { - Atividades de Extensão diversas: programas, } \\
\text { projetos e cursos } \\
\text { - Serviços de extensão tecnológica } \\
\text { - Voluntariado em ONGs }\end{array}$ & $\begin{array}{l}\text { https://www2.ifal.edu.br/ } \\
\underline{\text { campus/maceio/ensino/c }} \\
\underline{\text { ursos/superior/bacharela }} \\
\underline{\text { do-em-sistemas-de- }} \\
\underline{\text { informacao }}\end{array}$ \\
\hline IFSC & 2018 & $\begin{array}{l}\text { - Disciplina específica: Projeto de Extensão I } \\
\text { - Trabalho de Conclusão do Curso } \\
\text { - Atividades Complementares }\end{array}$ & $\begin{array}{l}\text { [Sewald-Júnior, Rech e } \\
\text { Rosa 2019] e } \\
\text { https://drive.google.com/ } \\
\text { file/d/1pPswsjEOM4Bx8 } \\
\text { GCRHNQop0XiTTpznA } \\
\text { 0s/view?usp=sharing }\end{array}$ \\
\hline $\begin{array}{l}\text { IFSULDEMINAS } \\
\text { Campus Machado }\end{array}$ & 2020 & - Práticas de Extensão & $\begin{array}{l}\text { https://portal.mch.ifsulde } \\
\text { minas.edu.br/projeto- } \\
\text { peda-curso-sis }\end{array}$ \\
\hline $\begin{array}{l}\text { UFAL } \\
\text { Penedo }\end{array}$ & 2018 & $\begin{array}{l}\text { - Programa de Extensão específico: "Sistemas } \\
\text { de Informação e Sociedade" } \\
\text { - Atividades Curriculares de Extensão (ACE) } \\
1,2,3,4,5 \text { e } 6 \text { com cursos, projetos de } \\
\text { extensão, projeto interdisciplinar e evento }\end{array}$ & $\begin{array}{l}\text { [Silva } 2019] \text { e } \\
\text { http://www.ufal.edu.br/a } \\
\text { rapiraca/graduacao/siste } \\
\underline{\text { mas-de- }} \\
\text { informacao/projeto- } \\
\text { pedagogico/ppc- } \\
\underline{\text { sistemas-de-informacao- }} \\
\underline{2017}\end{array}$ \\
\hline $\begin{array}{l}\text { UFC Campus } \\
\text { Crateús }\end{array}$ & 2018 & $\begin{array}{l}\text { - Disciplinas específicas: Projeto Integrador I, } \\
\text { II, III e IV }\end{array}$ & $\begin{array}{l}\text { http://www.crateus.ufc.b } \\
\underline{\mathrm{r}>\text { downloads }>\text { editais }}\end{array}$ \\
\hline UNIRIO & $\begin{array}{l}\text { Não } \\
\text { consta }\end{array}$ & $\begin{array}{l}\text { - Disciplinas específicas: Atividades } \\
\text { Complementares de Extensão (ACE) I, II, III } \\
\text { e IV }\end{array}$ & 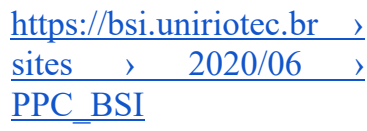 \\
\hline
\end{tabular}

As estratégias comumente adotadas são aquelas que envolveram a concepção de componentes curriculares nos formatos de disciplinas específicas de extensão, projetos e programas de extensão, disciplinas com caráter extensionista (como projetos integradores ou TCC), atendimento à comunidade, voluntariado, cursos e organização de eventos.

Percebe-se que, timidamente, as instituições de ensino estão reformulando seus projetos pedagógicos visando a solução de problemas da sociedade, mas que ainda existem propostas extensionistas com caráter apenas complementar ou extracurricular. Inclusive, uma das dificuldades enfrentadas foi localizar os arquivos dos PPC's nos sites 
dos cursos, o que obstaculizou uma análise mais aprofundada da organização didáticopedagógica. A maioria disponibiliza apenas a matriz curricular onde foi possível visualizar algumas disciplinas com nomes sugestivos de atividade de extensão, porém, a impossibilidade de acesso ao PPC não permitiu identificar se, de fato, foram devidamente curricularizadas.

\section{Considerações finais}

Os sistemas de informação estão cada vez mais disseminados na sociedade e as atividades com natureza extensionista permitem desenvolver a consciência social e despertar o compromisso dos discentes no enfrentamento de mudanças na realidade por meio de soluções tecnológicas e digitais.

Como foi possível observar, as possibilidades de estratégias são inesgotáveis e cabe a cada curso reconhecer seu ambiente local e regional para organizar didaticamente seus currículos voltados à extensão. Apesar das instituições de ensino já possuírem comissões próprias e resoluções específicas para regulamentar a curricularização da extensão, a tarefa de atualização dos PPC's ainda segue lenta, pois, dos 40 cursos analisados, apenas 6 tornaram a extensão curricularmente explícita. Portanto, o sobrevoo panorâmico que se almejou alcançar evidenciou que a ampla maioria dos projetos dos BSI's ainda se encontra em fase de adaptação frente ao desafio de repensar o contexto dos componentes curriculares em detrimento à mera creditação de horas de extensão.

Para trabalhos futuros planeja-se obter mais detalhes sobre as experiências identificadas a partir de uma consulta junto aos coordenadores dos cursos de modo a aprofundar as discussões e compreender como as conduções das tarefas de extensão estão sendo realizadas em cada uma das estratégias.

\section{Referências}

BRASIL. Ministério da Educação/Conselho Nacional de Educação (2018) "Resolução No 7/2018". Estabelece as Diretrizes para a Extensão na Educação Superior Brasileira e regimenta o disposto na Meta 12.7 da Lei ${ }^{\circ}$ 13.005/2014. Brasília-DF.

Imperatore, S. L. B. (2019) "Curricularização da Extensão: Experiência da Articulação Extensão-pesquisa-ensino-extensão como Potencializadora da Produção e Aplicação de Conhecimentos em Contextos Reais". Gramma Editora, 1a ed. Rio de Janeiro-RJ.

Imperatore, S. L. B., Pedde, V. e Imperatore, J. L. R. (2015) “Curricularizar a Extensão ou Extensionalizar o Currículo? Aportes Teóricos e Práticas de Integração Curricular da Extensão Ante a Estratégia 12.7 do PNE”, In: XV Colóquio Internacional de Gestão Universitária. Anais. Mar del Plata.

Serva, F. M. (2020) "A Extensão Universitária e sua Curricularização". Editora Lumen Juris: Rio de Janeiro-RJ.

Sewald-Júnior, E., Rech, G. A. e Rosa, V. S. D. (2019) “A construção do primeiro curso adequado a políticas de extensão no currículo no IFSC: planejamento pedagógico de sistemas de informação e ações iniciais”. Revista de Extensão do IFSC, ano 6, n.10.

Silva, A. A. (2019) "Programa de Curricularização da Extensão Universitária de Sistemas de Informação - UFAL/PROGRAD/CONSUNI/UE PENEDO", Revista Eletrônica Extensão em Debate, v.6, n.5, p. 24-35. 